\title{
Boosting employability through the use of Authentic Learning Scenarios
}

\author{
Angels Fitó Bertran, M.Jesús Martínez-Argüelles, Dolors Plana-Erta \\ Economy and Business Department, Universitat Oberta de Catalunya, Spain
}

\begin{abstract}
Education for employability is one of the greatest challenge for Higher education institutions in Europe, but especially in Spain. The European Higher Education Area assumes that competence development becomes crucial to connect higher education curricula with evolving labour market demands. The Authentic Learning Scenarios foster the competence development bringing work experience to the formal learning. Considering that online learning methodologies seems to have a relevant role into a life long learning perspective to achieve authentic learning environments is a singular challenge.

We have introduced the authentic learnig scenarios attributes into a specific subject and we have tested its impact on students competence profile. Apart from testing if the new subject design is effectively atuthentic, the findings show that when the learning process includes authenticity the students perception about their perfomance in the competence more relevant for the job market improves.
\end{abstract}

Keywords: Employability; Authentic learning; Generic skills; Financial education. 


\section{Introduction}

One of the cornerstones of the European Higher Education Area (EHEA) is its emphasis on a higher education that prepares graduates for a profession. Within this context, competencies play a key role in the design of degree courses because they constitute dynamic elements that enable higher education institutions to address the changing needs of society. In this setting, generic competencies become particularly relevant for the job market. The Higher Education programmes and curricula have to guarantee that the competency profile of graduates meets the job market needs. This context of education for employability that turns around the competence development requires innovative pedagogies. The Authentic Learning Scenarios (ALS) foster the competence development bringing work experience to the formal learning in Higher Education Institutions.

To assess if the introduction of authenticity in learning, as an attribute of learning tasks and environments, boosts increases students' employability through a better competence performance we have redesigned a subject (Financial statements analysis, included into an online bachelor of Business Administration) under the precepts established by ALS theory. The structure of the remainder of the paper is as follows: Section 2 summarizes the background of the ALS theory, Section 3 presents methodology, Section 4 shows the results and Section 5 presents the conclusions of the study.

\section{Review of literature}

Education for employability has been the mantra of the EHEA since its inception. The keystone of this reform is an emphasis on a career-oriented university education that enhances graduates' employability. Since then, the socioeconomic environment has undergone substantial changes that have reinforced the relevance of this founding principle based on employability. The most critical was the recent economic recession.

The will to strengthen the connection between higher education curricula with the demands of the labour market has modified the design of programs and learning strategies. In a macro level learning perspective, the most important change was the new competencebased orientation. Competencies came into a dynamic point of reference that gives universities the necessary flexibility for them to address the demands of a changing society (Tymon,2013; Gonzalez \& Wagenaar, 2003, 2005).

In this context, several papers have researched the competency framework that the job market requires to graduates, specifically business graduates (Burchell, Hodges, \& Rainsbury, 2001) and the gap between these and the competencies that graduates effectively acquires in the university (Hodges \& Burchell 2003). Despite the results shows many diferent sets of competencies and their relative importance, there seems to be some 
consensus on the fact that they all emphasise the importance of personal attributes above technical skills (Tymon, 2013). Taking into consideration these previous skill frameworks and as a part of an Erasmus plus Programme (Orellanas et al, 2017) we carried out an online focus grup involving teaching staff, undergraduates, graduates, career counsellors and employers' representatives from Germany, Sweden and Spain. As a result we obtained a taxonomy of the employability demanded.

In a micro level learning perspective, the challenge has been the reorientation of the different subjects towards a more labour connected performance. So, the design of the learning process through ALS is becoming a successful approach. While real businesses, together with traditional course teaching methods primarily have served as tools for the development of skills and authentic learning processes. It is a more radical approach in building an entire course of studying on authentic activities and tasks (Scalon, 2011).

A large scale of employers argue that, in order to boost the employability of graduates, it is essential to reduce the gap between the application of knowledge in the real work environment and the theoretical learning in the formal instruction. Too often students are taught in a largely decontextualized manner in the classroom (Resnick, 1987). According to (Brown, Collin \& Duguid, 1989) a way to bridge this gap is to the use a model of cognitive apprenticeship. This model is designed to "enculturate students into authentic practices through activity and social interaction" (p.37). These authors outline three fundamental characteristics of cognitive apprenticeship:

(1) Learners have continual access to models of expertise-in-use against which to refine their understanding of complex skills. (2) Apprentices often have several masters and have access to a variety of models of expertise which leads to the believe that there may be different ways to carry out a task, and that no one individual embodies all the knowledge and expertise. (3) Learners have the opportunity to observe other learners with varying degrees of skill. So, meaningful learning only occurs while it is embedded in a social and physical context. Cognitive apprenticeship originates in the interaction of various components, such as the learner, the learning environment and the task (Barab, Squire \& Deuber, 2000).

Following this approach, different authors have made contributions on how learning should be developed through authentic practices based on authentic activities and social interaction. While some authors (Savery \& Duffy, 1996) have argued that only realproblem contexts should be presented to guarantee authenticity, other authors (Alessi, 2000; Herrington \& Herrington, 2006) shown that maximum fidelity, does not necessarily lead to maximum effectiveness in learning. Rather than the physical authenticity, the cognitive authenticity must be the cornerstone of the learning design (Smith, 1987; Herrington, Oliver \& Reeves, 2003). In any case, if the students are not learning in a context of 
internship in a real company, they must be provided with an authentic learning environment (Herrington, Oliver \& Reeves, 2007). This context should reflect how knowledge will be applied in practice, through authentic activities. Previous studies have established that learning is best facilitated in learning environments that reflects the way the knowledge will be used in real life (Herrington, Reeves \& Oliver, 2010). The authors have identified nine elements of authentic learning as criteria for assessing the degree of authenticity of a learning environment. These criteria are (Herrington, Reeves \& Oliver, 2010):

(1) Provide authentic context that reflects the way the knowledge will be used in real-life. (2) Provide authentic activities. The e-learning courses need to provide ill-defined activities that have real-world relevance, and which present a single complex task to be completed over a sustained period of time. (3) Provide access to expert performances and the modelling of processes. Authors recommend methods which are not teacher-centric, but border-crossing and collaborative. (4) Provide multiple roles and perspectives. Authors recommend to give opportunities to work with agents from other professions/disciplines. (5) Support collaborative construction of knowledge. This is especially relevant in an elearning context. (6) Promote reflection. The e-learning course needs to establish an authentic context and task to enable meaningful reflection and self-reflection. (7) Promote articulation. The authentic tasks to do need to incorporate inherent opportunities to articulate the public presentation of arguments to enable defence of a position. (8) Provide coaching and scaffolding. The authors emphasize that this coaching and scaffolding role can be exercised not only by teachers but by peers and experts. (9) Provide authentic assessment of learning within the tasks. The assessment should be seamlessly integrated with the activity and should provide appropriate criteria for scoring the complex tasks of the students

Within this context and given the opportunities that offers this pedagogical approach, we have designed and implemented an authentic learning scenario in a specific subject to answer the main research question: Do the ALS improve the required skill to foster the employability of Higher Education graduates? Therefore, we have tried to answer this question in to steps: a) Does the design of the subject reflects an authentic learning scenario? b) Does the authentic learning scenario boost the employable competences of the students?

\section{Metodology}

The study has been focused on the application of ALS in an online environment as it has been made at Universitat Oberta de Catalunya, a fully online university with headquarters. Also, it has been applied to a subject on a degree with a large volume of students and graduates the Bachelor's degree in Business Administration (BA). The degree of BA, which 
has more than 5,000 students, constitutes one of the key degrees of the University. It is also a regular educational offer in universities around the world. The subject, named Analysis of Financial Statements, is a compulsory and advanced subject within the degree. Besides, it is very relevant to one of the most common professional profiles of graduates in BA, a financial management assistant.

The study was carried out with experimental design of one factor. It carried out during a full semester on the students in the subject of analysis of the financial statements. The control group was formed by the students who had studied the subject the previous semester to the one of the study. The response to the control group survey was of 86 students (25\% of the total) and the study group of 49 students (15\% of the total). The descriptions of age and sex are similar in both samples. In addition, $60 \%$ of the students that have answered, nowadays have jobs related to the studies they are currently studying.

\subsection{The learning environmental and the tasks}

The principles of authentic learning guided the redesign of the subject, and the learning activities were focused on performing realistic and complex tasks. The virtual class recreated through videos the meetings held between the Financial Director of a company, the professor of the subject, and his newly appointed assistant, the student. The objective set for the associate was to prepare a professional financial report about the economic and financial situation of the company that would be presented by the Financial Director at the next Board of Directors. In the initial meeting (first video), the assistant is commissioned by the head, and four more meetings are arranged to compare the evolution of the assignment.

Students were asked to carry out four learning activities on an individual basis that would provide them with the theoretical and practical foundation for preparing the financial report. However, in each of the four activities, the financial director raised an uncomfortable question to the assistant. He wanted to know his opinion regarding the impact of the conclusions obtained in the decision making process that affect other departments of the company such as the general management, production, human resources or marketing department. The assessment was continued throughout the whole semester and the student received for each activity a qualification and a personalized comment that could be used to improve the final report.

\subsection{Measure instrument and data analysis}

The tool for measuring it has been an anonymous online survey for all students enrolled at the end of the teaching period (354 in the control group and 329 for the study group. The survey included a set of demographics, a group of questions related to the achievement of the 16 skills that promote employability identified Erasmus plus Program (Orellanas et al, 
2017) and another group of questions related to the performance or not of the 9 elements that characterize an authentic learning (Herrington \& Oliver, 2000; Herrington, Reeves \& Oliver, 2010). The answers were Likert type of five degrees. The analysis of the data consisted in the comparison of the averages between the control group and the study group. As the variables did not follow the distribution of proportions of the Normal Law, was used the $U$ test of Mann-Whitney's for two independent samples.

\section{Results}

With the analysis carried out, the two questions raised in the study have been answered. About the first of them Does the design of the subject reflects an authentic learning scenario? the answer is yes as shown in table 1 . The average and standard deviation of the attributes indicate that the redesign of the subject has allowed to improve the perception of the students on to what extent the subject reflects the reality of the professional context of a financial director (values greater than 3 except in the item related to group work, logically if we consider that the job of the job that is replicated is primarily individual and not group). And the contrast statistic indicates that the differences are significant in all the elements except in two of them, not invalidating the results because the redesign did not need to increase the high support that they already received from the teacher nor the neatness and refinement of the performances.

Regarding the second question Does the authentic learning scenario boost the employable competencies of the students? shows in table 2 that students have perceived that skills for employability, according to the Skill-up study, have improved in the study group (averages almost in all the items of the higher study group those of the control group). And this improvement is statistically significant in nearly all of them. Therefore, the students perceive that, with the current design of the subject, the level of competence for employability is higher. But not only that, but also the students themselves see that they have improved, especially in those that are relevant to their employability.

\section{Conclusions}

The increase in employability is one of the fundamental objectives of the European Higher Education Area. Also, UNESCO in its 2030 agenda seeks to ensure inclusive and quality education for all and promoting lifelong learning (ODS-4). At this point, e-learning plays a key role as a provider of lifelong learning.

According to the literature, the use of ALS contributes to the improvement of student employability. Through this research, it has been shown how these scenarios also contribute to improving employability in an e-learning context and in a subject of a degree that is not 
practical. It is necessary to continue investigating to analyze to what extent these results are extrapolated to other subjects and disciplines.

Table 1. Statistic of the elements of authentic learning

\begin{tabular}{|c|c|c|c|}
\hline \multirow{3}{*}{ Authentic learning attributes } & \multicolumn{2}{|c|}{ Descriptive statistics } & \multirow{3}{*}{$\begin{array}{l}\text { Contrast } \\
\text { statistic }^{2}\end{array}$} \\
\hline & Study. $n=49$. & Control. $n=86$. & \\
\hline & $\mathrm{M}(\mathrm{SD})^{1}$ & $\mathrm{M}(\mathrm{SD})^{1}$ & \\
\hline Context course represented real & $\mathrm{M}=4,49(0,51)$ & $\mathrm{M}=4,08(0,83)$ & Sig $=0,004$ \\
\hline Task real & $M=4,39(0,61)$ & $\mathrm{M}=4,02(0,91)$ & Sig $=0,026$ \\
\hline Task complex problem & $M=4,16(0,75)$ & $M=3,76(0,93)$ & Sig $=0,017$ \\
\hline Chose information & $\mathrm{M}=4,39(0,70)$ & $M=3,84(0,93)$ & Sig $=0,000$ \\
\hline Externalizable task and strategies & $M=4,39(0,53)$ & $M=3,90(0,78)$ & Sig $=0,000$ \\
\hline Access expert & $\mathrm{M}=4,24(0,88)$ & $\mathrm{M}=3,36(1,12)$ & Sig $=\mathbf{0 , 0 0 0}$ \\
\hline Different view & $\mathrm{M}=4,12(0,73)$ & $M=3,55(1,05)$ & Sig $=0,001$ \\
\hline Group effort, rather individual effort & $\mathrm{M}=3,10(1,39)$ & $\mathrm{M}=1,81(1,08)$ & Sig $=0,000$ \\
\hline Decisions complete task & $M=4,20(0,87)$ & $M=3,24(1,08)$ & Sig $=0,000$ \\
\hline Compare experts & $M=3,82(1,11)$ & $M=2,94(1,31)$ & Sig $=0,000$ \\
\hline Reflection group & $\mathrm{M}=2,94(1,38)$ & $M=1,87(1,06)$ & Sig $=0,000$ \\
\hline Task enabled arguments & $\mathrm{M}=3,80(1,04)$ & $M=3,20(1,24)$ & Sig $=0,004$ \\
\hline Teacher support & $\mathrm{M}=4,27(0,86)$ & $\mathrm{M}=4,10(1,02)$ & Sig $=0,417$ \\
\hline Performance polished & $\mathrm{M}=4,12(0,70)$ & $M=4,19(0,86)$ & Sig $=0,365$ \\
\hline Activity extend periods & $M=4,16(0,90)$ & $M=3,85(0,98)$ & Sig $=\mathbf{0 , 0 3 7}$ \\
\hline Multiple assessment & $M=4,12(0,75)$ & $M=3,27(1,21)$ & Sig $=0,000$ \\
\hline
\end{tabular}


Table 2. Statistical of the improvement of the competences for the employability ordered according to the relevance of each one of the competences assigned by the student

\begin{tabular}{|c|c|c|c|c|}
\hline \multirow{2}{*}{$\begin{array}{l}\text { Competences for } \\
\text { employability }\end{array}$} & \multirow{2}{*}{$\begin{array}{c}\text { Competence } \\
\text { relevance } \\
\% \text { total }\end{array}$} & \multicolumn{2}{|c|}{ Descriptive statistics } & \multirow{2}{*}{$\begin{array}{l}\text { Contrast } \\
\text { statistic }^{2}\end{array}$} \\
\hline & & $\begin{array}{c}\text { Study. } n=49 . \\
M(S D)^{1}\end{array}$ & $\begin{array}{c}\text { Control. } \mathrm{n}=86 \\
\mathrm{M}(\mathrm{SD})^{1}\end{array}$ & \\
\hline Analytical thinking & 14,1 & $\mathrm{M}=4,55(0,94)$ & $\mathrm{M}=4,15(0,78)$ & Sig. $=0,000$ \\
\hline Problem-solving & 12,5 & $M=4,27(0,93)$ & $M=3,77(0,86)$ & Sig. $=\mathbf{0 , 0 0 0}$ \\
\hline Decision making & 9,9 & $M=4,31(1,14)$ & $M=3,92(0,88)$ & Sig. $=\mathbf{0 , 0 0 0}$ \\
\hline Teamwork & 9,7 & $M=2,69(1,53)$ & $M=1,80(0,92)$ & Sig. $=\mathbf{0 , 0 1 0}$ \\
\hline Foreing lenguage & 7,3 & $M=2,57(1,56)$ & $\mathrm{M}=1,560,81)$ & Sig. $=\mathbf{0 , 0 0 0}$ \\
\hline Comunication skills & 6,4 & $M=3,53(1,28)$ & $M=2,67(1,21)$ & Sig. $=0,000$ \\
\hline Digital skills & 5,9 & $\mathrm{M}=3,90(1,16)$ & $M=2,92(1,11)$ & Sig. $=\mathbf{0 , 0 0 0}$ \\
\hline Self-management & 5,9 & $\mathrm{M}=4,31(0,92)$ & $M=3,99(0,91)$ & Sig. $=0,018$ \\
\hline Results orientation & 5,7 & $\mathrm{M}=4,22(0,80)$ & $\mathrm{M}=4,08(0,76)$ & Sig. $=0,216$ \\
\hline Capabilily cope with changes & 5,1 & $M=3,67(1,27)$ & $M=3,02(1,26)$ & Sig. $=0,003$ \\
\hline Creative thinking & 4,8 & $M=3,96(0,98)$ & $M=3,26(1,05)$ & Sig. $=\mathbf{0 , 0 0 0}$ \\
\hline Stress management & 4,0 & $M=3,59(1,27)$ & $M=2,50(1,31)$ & Sig. $=\mathbf{0 , 0 0 0}$ \\
\hline Conflict management & 3,5 & $M=3,49(1,37)$ & $M=2,51(1,25)$ & Sig. $=\mathbf{0 , 0 0 0}$ \\
\hline Learning to learn & 3,1 & $\mathrm{M}=4,12(1,03)$ & $\mathrm{M}=3,40(1,09)$ & Sig. $=\mathbf{0 , 0 0 0}$ \\
\hline Cross-cultural and diversity & 1,1 & $M=2,98(1,42)$ & $\mathrm{M}=2,51(1,18)$ & Sig. $=0,047$ \\
\hline Subject-specific skills & 1,1 & $M=4,10(0,96)$ & $M=4,19(0,90)$ & Sig. $=0,630$ \\
\hline
\end{tabular}

${ }^{1} \mathrm{M}=$ Average; $\mathrm{SD}=$ Standard Desviation. ${ }^{2}$ Contrast done with the nonparametric test U from Mann-Whitney

\section{References}

Alessi, S. (2000). Designing educational support in system-dynamics interactive learning environments. Simulation and Gaming, 31(2), 178-196.

Barab, S.A., Squire, K.D., \& Dueber, W. (2000). A Co-Evolutionary Model for Supporting the Emergence of Authenticity. Educational Technology Research and Development, 48(2), 37-62.

Brown, J. S., Collin, A., \& Duguid, P. (1989). Situated cognition and the culture of learning. Educational Researcher, 18(1), 32-42. 
Burchell, N., Hodges, D. y Rainsbury, E. (2001). What competencies do business graduates require? Perspectives of New Zealand stakeholders. Journal of Cooperative Education, 35(2-3), 11-20.

González, J., \& Wagenaar, R. (2003). Tuning educational structures in Europe. Final report. Pilot Project-Phase 1 (ANECA, 2003).

González, J., \& Wagenaar, R. (2005). Tuning educational structures in Europe. Final report. Pilot Project-Phase 2 (ANECA, 2005).

Herrington, A., \& Herrington, J. (2006). What is an authentic learning environment? In A. Herrington \& J. Herrington (Eds.), Authentic learning environments in higher education (pp. 1-13). Hershey, PA: Information Science Publishing.

Herrington, J., Oliver, R., \& Reeves, T.C. (2003). Patterns of engagement in authentic online learning environments. Australian Journal of Educational Technology. 19(1), 5971

Herrington, J; Reeves, T.C.; \& Oliver, R. (2007). Immersive Learning Technologies: Realism and Online Authentic Learning. Journal of Computing in Higher Education, Vol. 19(1), 80-99.

Herrington, J., Reeves, T.C. \& Oliver, R. (2010). A guide to authentic e-learning. London and New York: Routledge.

Hodges \& Burchell 2003. Business graduate competencies: Employers' views on importance and performance. Asia-Pacific Journal of Cooperative Education, 4(2), 1622.

Ornellas, A. (cord.); Edman, E.; Falkner, K.; Fuhrmann, F.; Vilanova, N.; Candel, R.; Köhl, S. (2017). Good practices in connecting workplace and learning in higher education. Working paper. Skill-up project.

Resnick, L. (1987). Learning in School and Out. Educational Researcher, 16(9), 13-20.

Savery, J.R., \& Duffy, T.M. (1996). Problem based learning: An instructional model and its constructivist framework. In B.G. Wilson (Ed.), Constructivist learning environments: Case studies in instructional design(pp. 135-148). Englewood Cliffs, NJ: Educational Technology.

Scanlon, L. (2011). Becoming a professional. In Lesley Scanlon (Eds.), Becoming a Professional: an Interdisciplinary Analysis of Professional Learning, (pp. 13-32). Dordrecht: Springer

Smith, P.E. (1987). Simulating the classroom with media and computers. Simulation and Games, 18(3), 395-413.

Tymon, A. (2013). The student perspective on employability. Studies in higher education, 38(6), 841-856. 